\title{
Evaluation of stitch length accuracy of embroidery machine by different speed and step
}

\author{
Daniela Sofronova ${ }^{1, *}$ and Yavor Sofronov ${ }^{2}$ \\ ${ }^{1}$ Technical University of Sofia, Department of Textiles Technologies, 1000 Sofia, Bulgaria \\ ${ }^{2}$ Technical University of Sofia, Department of Theory of Mechanisms and Machines, 1000 Sofia, \\ Bulgaria
}

\begin{abstract}
The key factor for high quality embroidery is the precision with which the individual stitches are realized in the plane of frame XY. For this purpose, the dispersion in the size of each step on $\mathrm{X}$ and $\mathrm{Y}$ axes are measured, depending on the step length and the machine speed. The studies were carried out in the entire stroke of the two axes. To evaluate only the positioning error of each individual step the measurements without removing the embroidery fabric from the frame are made in order to eliminate deformations caused by fabric relaxations. The results obtained are particularly relevant for evaluating the ability to produce elements as small as possible.
\end{abstract}

\section{Introduction}

Machine embroidery plays an important role in the manufacturing process not only for standard embroideries but also for smart textiles production. The smart textiles design using machine embroidery technology is relatively a new process with many unknowns. In the most cases conductive threads are used, which have different physico-mechanical behaviour from ordinary ones. Regardless of the thread type, knowledge of the effect of each factor of the technological process is important not only for the stage of embroidery design, but also for achieving low cost products.

There are many publications dedicated to the influence of technological and design parameters on the embroidery quality [1-7]. In [1] a case study on the defects in industrial manufacturing of embroidered textiles is done. It was report that the most frequently found defects were related to mixed problems in the design and manufacturing stages. Some authors studied the difference between the embroidered element and its designed digital image [2-4]. It is proven the dependence of the design and technology parameters on the quality. In [2] the studied parameters are the type of stitch row, stitch density and thread type and in [3] the influence of the embroidery direction (weft, warp and bias) is also investigated. An analysis of shape nonconformity between produced circular fill element and its design is made in [4]. It is observed that when the stitch direction goes towards the

\footnotetext{
* Corresponding author: dcholeva@tu-sofia.bg
} 
middle of the embroidered element, the considerable stitch concentration in the centre is occurred. The effect of ordinary embroidery threads on buckling of fabric inside of the embroidered element is discussed in [5] and the buckling by materials with different physical properties inside embroidered elements in [6]. The results showed that fabric structure indicators such as linear filling and linear porosity influence the formation of the height and shape of the buckling waves inside the embroidered element. A methodology of technology optimization based on the measurement the geometric parameters of rectangular object is proposed in [7].

Some authors associate the textile embroidery product quality and the frame vibrations which arising during machine operation [8-12]. In [8] the existing systems for measuring, monitoring and analysis the machine vibration from textile industry are considered. The authors report on online systems involving tri axial piezoelectric accelerometer or laser vibrometer and FFT spectrum analysis system. And experimental researches on the embroidery machine vibrations are done in $[9,11]$. The maximum measured vibration level in [9] is $12.9 \mathrm{~mm} / \mathrm{s}$, which could lead to significantly reducing the machine reliability. The authors also performed experiments by different bases on which the embroidery machines are positioned. In [10] the relationship between the maximum vibration amplitude and the embroidering direction and embroidery patterns is investigated. In [11] the authors developed a fuzzy decision system based on Matlab ${ }^{\circledR}$ software for an optimal regime of machine work considering the levels of vibrations and noises of the embroidery machine and the geometric entities.

Despite considerable research in the field, there are no studies reporting the accuracy of the frame positioning, which is an important indicator for any positioning machine. The frame in embroidery machines performs planar movement before each needle puncture to form a single stitch, which in turn is the basis for any stitch row construction. Furthermore, the frame positioning has a direct impact on the quality of embroidered elements, as it is also affected by machine vibrations. Therefore, the purpose of this article is to determine the accuracy of linear frame movement and to evaluate the individual stitch length accuracy with different machine embroidery speed and stitch steps.

\subsection{Materials}

For the purposes of the experimental study a woven fabric in plain weave is used, which has the following parameters: a thickness $0,315 \mathrm{~mm}$, an area density $125 \mathrm{~g} / \mathrm{m}^{2}$, course and wale densities respectively 24 and 21 loops $/ \mathrm{cm}$. The fabric is stabilized with one layer nonwoven material, tear way type and area density $45 \mathrm{~g} / \mathrm{m}^{2}$. The upper thread is the most commonly used in machine embroidery $100 \%$ viscose filament $135 \mathrm{x} 2 \mathrm{dtex}$ and the bobbin thread is $100 \%$ Polyester $120 \times 2$ dtex.

\subsection{Technological parameters}

The embroidery design is created with Digitizer MB V 2.0 software. An example of the digital view is presented on Figure 1, from which it can be seen that the embroidery object is digitized with the basic stitch row: single stitch run 2, which follows left $\left(y_{1}\right)-$ up $\left(x_{1}\right)$ right $\left(y_{2}\right)$ - down $\left(x_{2}\right)$, the frame outline 1 . The most significant accuracy deviations are usually expected exactly in the boundary zones. The distance between the digitized stitch row and the frame outline is $2 \mathrm{~mm}$.

A total of 3 design variants have been developed distinguished only in the stitch step: 1 $\mathrm{mm}, 2 \mathrm{~mm}$ and $4 \mathrm{~mm}$. In all design bar-tacks of the first and the last stitch, pull compensations $0.2 \mathrm{~mm}$ and no undelay stitch rows are set. 
All samples are embroidered on one head machine Janome MB4, equipped with needles №90 and the largest for the machine frame, in 3 operating machine speed: 400, 600 and 800 $\min ^{-1}$. The other machine settings remain constants.

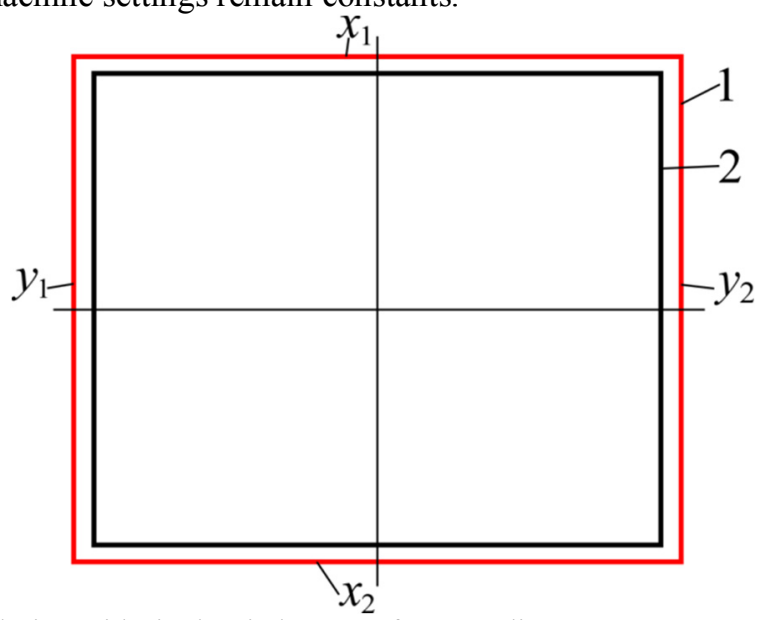

Fig. 1. Embroidery design with single stitch row at frame outline.

Table 1. Embroidery design variants.

\begin{tabular}{|c|c|c|c|}
\hline № & Stitch step, mm & Machine speed, min $^{-1}$ & Sample code \\
\hline 1 & \multirow[t]{3}{*}{ 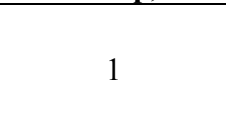 } & 400 & S1-4 \\
\hline 2 & & 600 & S1-6 \\
\hline 3 & & 800 & S1-8 \\
\hline 4 & \multirow{3}{*}{2} & 400 & S2-4 \\
\hline 5 & & 600 & S2-6 \\
\hline 6 & & 800 & S2-8 \\
\hline 7 & \multirow{3}{*}{4} & 400 & S4-4 \\
\hline 8 & & 600 & S4-6 \\
\hline 9 & & 800 & S4-8 \\
\hline
\end{tabular}

A total of 9 test variants were obtained, which are described in Table 1. Each of the variants was tested with 3 specimens.

\subsection{Methods}

The samples are preconditioned and the tests are carried out under standard atmospheric conditions for conditioning and testing of textiles according to BDS ISO 139:1993.

The thickness of the fabric with Schmidt DM2000T gauge with $0.01 \mathrm{~mm}$ accuracy at 49 $\mathrm{kPa}$ is measured. Five specimens according BDS EN ISO 5084:2002 are tested. The area density is determined according BDS EN 12127:2000 and the course and wale density according BDS EN 1049-2:2002. Five specimens were tested for each parameter. Structure parameter measurement error varied from $0,62 \%$ to $3,15 \%$.

The evaluation of stitch step accuracy is performed by measuring the $x$ and $y$ coordinates of each individual stitch. For this purpose a manual vision measuring system MUMA OVM V4.10.08.110429_RLT with $0,001 \mathrm{~mm}$ scale resolution and 3 microns accuracy is used. After embroidery, the fabric is not removed from the frame and it is positioned on the base of the measuring system together with the frame. The aim is to avoid possible shrinkage of the fabric, which could lead to a change in the stitch location. The 
measurement is performed by indicating the puncture points of the needle. An example of the specimen view is shown in Figure 2. The measurement error is mainly due to the thickness of the thread, which in the present work is in the range of $0,149 \mathrm{~mm}$. The diameter of a thread is determined theoretically and experimentally by measuring the thickness with a weight of $240 \mathrm{~g} / \mathrm{m}^{2}$ in 10 places.

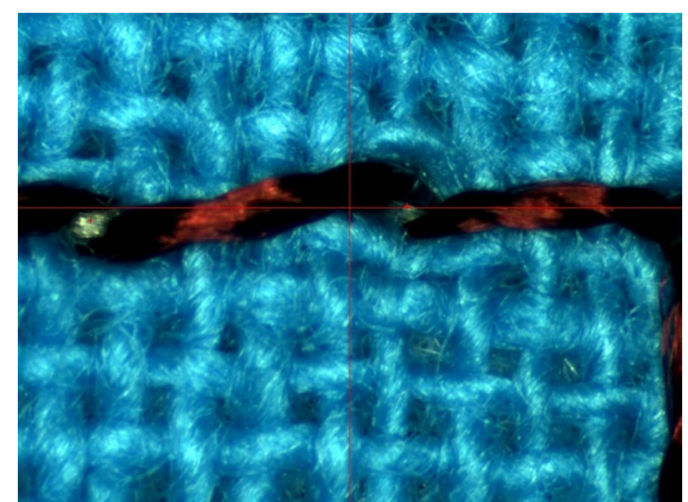

Fig. 2. Specimen view in the vision measuring system.

The change in the step length is calculated:

$$
\Delta l=\frac{l_{1}-l_{0}}{l_{0}} \cdot 100, \%
$$

Where: $l_{1}$ is the measured step, mm;

$l_{0}$-defined step, $\mathrm{mm}$.

The deviation of movement straightness on the axes will be determined by calculating linear regression analysis. The used equation is as follow:

$$
y=A \cdot x+B
$$

Where: $y$ is the direction transversal to movement, $\mathrm{mm}$; $x$ - movement direction, $\mathrm{mm}$; $A$ - linear coefficient; $B-$ coefficient showing where the line crosses $y$.

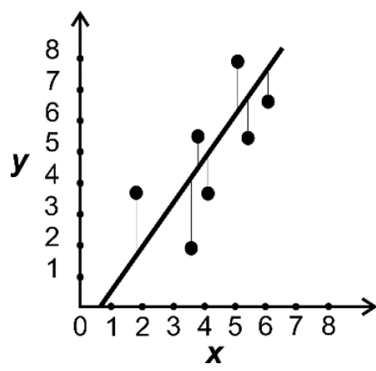

Fig. 3. Linear regression model.

Figure 3 shows a graph illustrating the deviation of the points from the straight line. This type of analysis is used to exclude the error from the orientation of the frame when it 
was transferring to the measuring system. The kinematic errors are included in the total positioning error.

All results from the measuring system software are downloaded and processed in Microsoft Excel.

\section{Experimental results and discussion}

From the performed linear regression analysis some statistical indicators were obtained, which reflecting the deviation from the straightness of the stitch row in all four axes of the frame. The results for the case for $2 \mathrm{~mm}$ stitch step are shown in Table 2.

The standard error for S1-8 has max value of $0,140 \mathrm{~mm}$ for axis $y_{1}$ and $0,109 \mathrm{~mm}$ for axis $x_{2}$. Increasing the operating speed of the machine leads to an increase in the standard error by $0,0133 \mathrm{~mm}$ for $x$ and $y$ axis by $1 \mathrm{~mm}$ stitch step. The min and the max deviations of the linearity on axis $x_{1}$ and $y_{2}$ could be seen respectively on the graphs on the Figure 4 and Figure 5. For axis $x_{1}$ the min deviation for S1-4 is $-0,160 \mathrm{~mm}$ and reaches to $-0,237$ $\mathrm{mm}$ for S1-8. The max value of deviation moves within $0,159 \div 0,174 \mathrm{~mm}$. For axis $y_{2}$ the min deviation is $-0,223 \mathrm{~mm}$ by low speed and $-0,350 \mathrm{~mm}$ for higher speed. The max deviation is from $0,245 \div 0,352 \mathrm{~mm}$.

Table 2. Experimental results for the deviation from straightness for $2 \mathrm{~mm}$ stitch step

\begin{tabular}{|c|c|c|c|c|c|}
\hline Samples & Frame & \multirow{2}{*}{$\begin{array}{c}\text { Standard } \\
\text { Axis }\end{array}$} & \multirow{2}{*}{$\begin{array}{c}\text { Number } \\
\text { error, mm }\end{array}$} & \multicolumn{2}{|c|}{ of points } \\
\cline { 5 - 6 } & $x_{1}$ & 0,096 & 99 & min & max \\
\hline \multirow{4}{*}{ S2-4 } & $x_{1}$ & 101 & $-0,205$ & 0,276 \\
\cline { 2 - 6 } & $x_{2}$ & 0,0785 & 99 & $-0,155$ & 0,222 \\
\cline { 2 - 6 } & $y_{1}$ & 0,094 & 101 & $-0,276$ & 0,265 \\
\cline { 2 - 6 } & $y_{2}$ & 0,106 & 100 & $-0,197$ & 0,142 \\
\hline S2-6 & $x_{1}$ & 0,077 & 100 & $-0,186$ & 0,256 \\
\cline { 2 - 6 } & $x_{2}$ & 0,098 & 100 & $-0,217$ & 0,240 \\
\cline { 2 - 6 } & $y_{1}$ & 0,113 & 100 & $-0,212$ & 0,234 \\
\cline { 2 - 6 } & $y_{2}$ & 0,108 & 100 & $-0,201$ & 0,163 \\
\hline \multirow{4}{*}{ S2-8 } & $x_{1}$ & 0,079 & 102 & $-0,244$ & 0,305 \\
\cline { 2 - 6 } & $x_{2}$ & 0,101 & 101 & $-0,182$ & 0,261 \\
\cline { 2 - 6 } & $y_{1}$ & 0,096 & 100 & $-0,241$ & 0,291 \\
\cline { 2 - 6 } & $y_{2}$ & 0,113 & & & \\
\hline
\end{tabular}

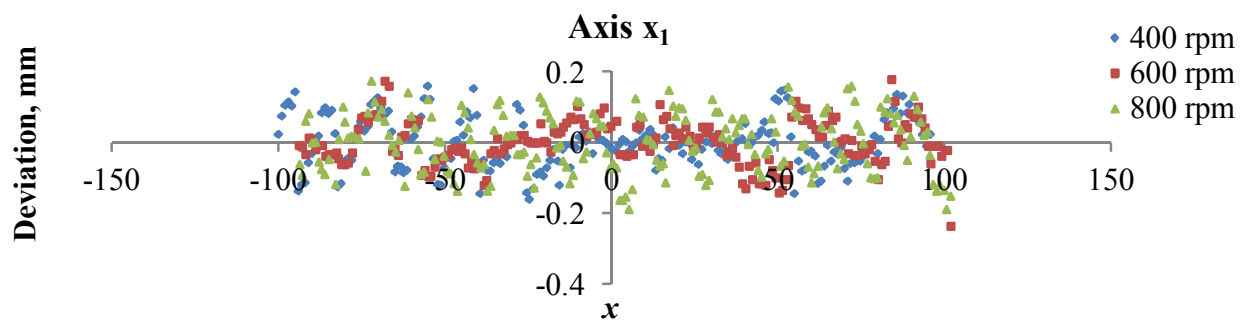

Fig. 4. Deviation of linearity by axis $x_{1}$ in the case of $1 \mathrm{~mm}$ stitch step. 


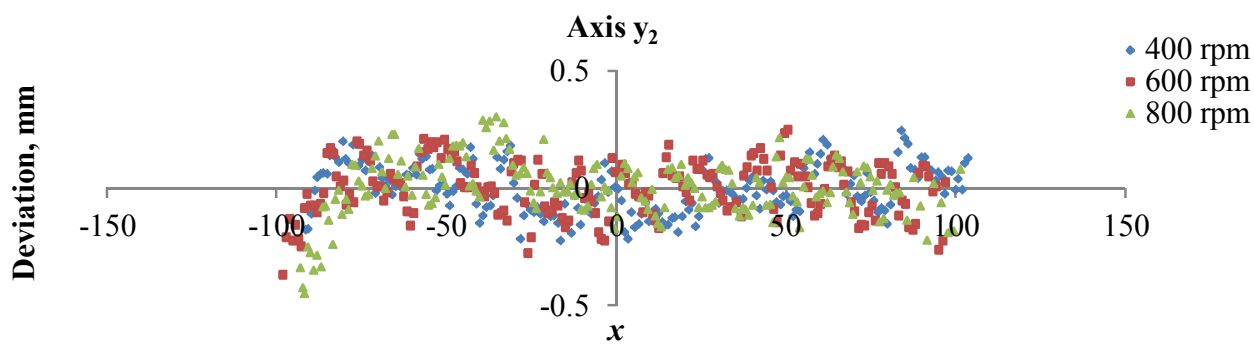

Fig. 5. Deviation of linearity by axis $y_{2}$ in the case of $1 \mathrm{~mm}$ stitch step.

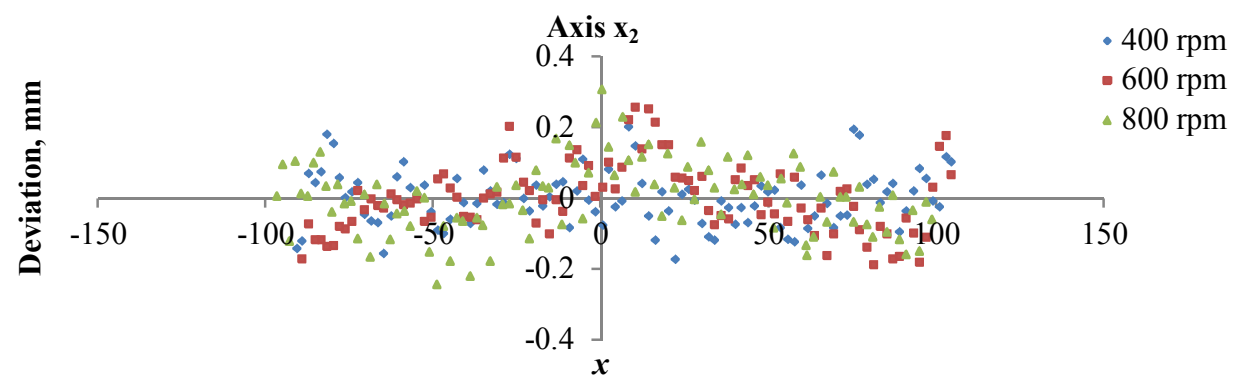

Fig. 6. Deviation of linearity by axis $x_{2}$ in the case of $2 \mathrm{~mm}$ stitch step.

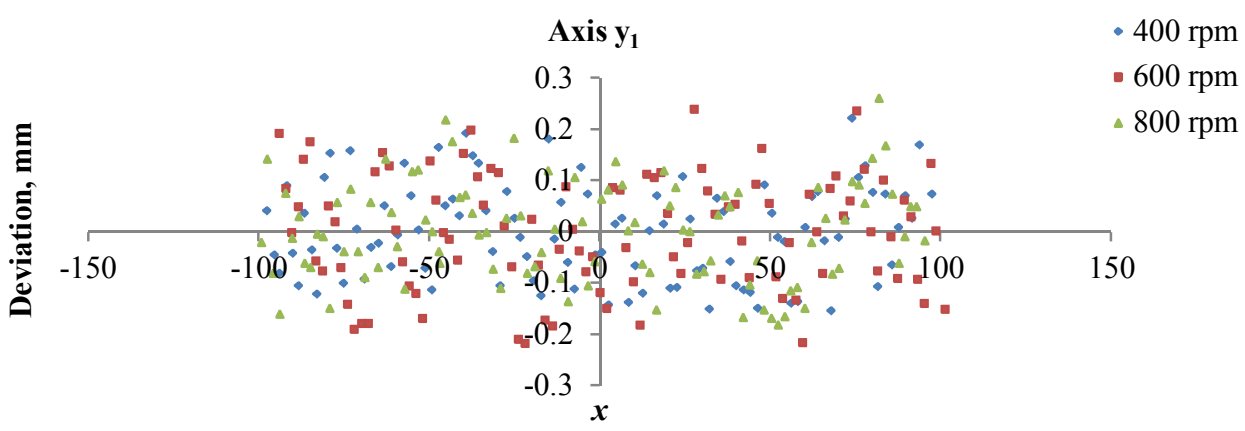

Fig. 7. Deviation of linearity by axis $y_{1}$ in the case of $2 \mathrm{~mm}$ stitch step.

In the samples embroidered with stitch step $2 \mathrm{~mm}$ there is a tendency to increase the min and max deviation with increasing speed for $x_{2}$ axis by between $0,07 \div 0,1 \mathrm{~mm}$. For the other axes this difference is smaller - about $0,01 \div 0,02 \mathrm{~mm}$. In the standard error there is increase of $0,02 \mathrm{~mm}$ at the $x_{2}$ axis, while in the other axes it is smaller. The deviation from the linearity for the samples with stich step $2 \mathrm{~mm}$ are shown in Figures 6 and 7 respectively for $x_{2}$ and $y_{1}$.

The standard error for S4-4 is higher for $x_{2}$ axis, which is furthest from the stand. For all axes it is within $0,077 \div 0,146 \mathrm{~mm}$. The increased stitch step does not increase the standard error at high speed, as the embroidery process is actually performed at lower speed than was set. For axis $x_{1}$ the min deviation for S4-4 is $-0,174 \mathrm{~mm}$ and for S4-6 -0,274 mm. The max value of deviation is within $0,143 \div 0,269 \mathrm{~mm}$. For the other three axes no significant change in the min and max deviation was observed.

The adjusted $\mathrm{R}$ square for $1 \mathrm{~mm}$ stitch step is between $0,922 \div 0.999$ for the three operating modes of the machine, which shows a very high correlation. By $2 \mathrm{~mm}$ stitch step it is $0,798 \div 0,997$, and for $4 \mathrm{~mm}-0,961 \div 0,999$. 


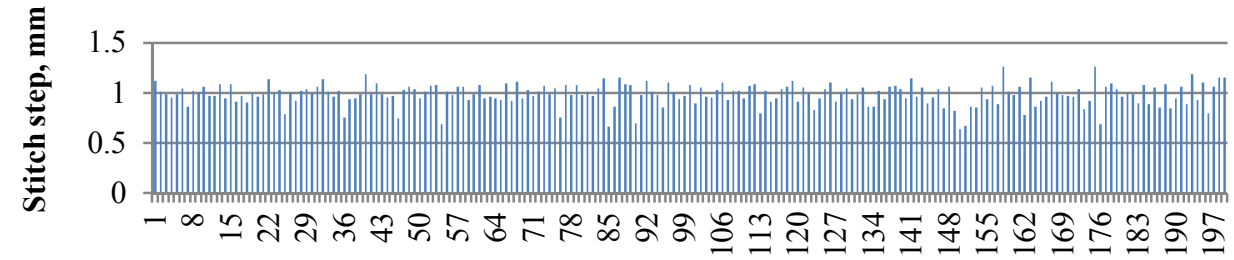

Number of needle puncture points

Fig. 8. Deviation from stitch step by S1-4 for axis $x_{1}$.

From the data obtained from the measuring system, the change in the step length of each individual stitch could be found. Figure 8 shows an example for sample S1-4 on axis $x_{1}$. The average value of the stitch step is $0,989 \pm 0,106 \mathrm{~mm}$. The results are similar for the other rpm as by $800 \mathrm{rpm}$ it is $0,994 \pm 0,093 \mathrm{~mm}$. The deviation in single stitch length is similar and for the other axes. For example, on axis $y_{2}$ the average stitch length is $0,9855 \pm 0,1096 \mathrm{~mm}$ by 400 and $600 \mathrm{rpm}$, and $0,990 \pm 0,128 \mathrm{~mm}$ by $800 \mathrm{rpm}$.

By samples embroidered with $2 \mathrm{~mm}$ stitch step line the average value is around $1,9775 \pm 0,235 \mathrm{~mm}$ for all axes and by different speed. The situation is similar with the samples S4-4, S4-6 and S4-8, where the average value on all axes varies between $3,886 \pm 0,168 \mathrm{~mm}$ and $3,992 \pm 0,139 \mathrm{~mm}$.

\section{Conclusions}

Embroidery technology is still evolving because it provides an opportunity for personalization of products as well as for production of wearable smart textiles. The accuracy is a key factor in achieving high quality embroidered motifs. It is also extremely important for the proper functioning of smart textiles. The verification of the deviation from straightness and the error in the stitch step give a complex assessment of the accuracy of the process.

For adequate assessment of accuracy, coordinate measurement of the stitches was used and the deviation from straightness was calculated. Studies have been performed within the machine range at different stitch steps and at different stitch formation frequencies. The standard error for the four axes varies from $0,062 \mathrm{~mm}$ to $0,146 \mathrm{~mm}$, while the minimum and maximum deviations respectively from $-0,160 \div-0,369 \mathrm{~mm}$ and $0,149 \div 0,384 \mathrm{~mm}$. The highest values are observed for the $x_{2}$ axis and the axes $y_{1}$ and $y_{3}$. The axis $x_{1}$ of the frame is located closest to the stand and it is the most stabile during embroidery process.

This paper is written in the framework of a project No. 201PR0005-02 "Establishment of e-textiles for pressure control on the body in bedridden patients" by SRC at TU-Sofia.

\section{References}

1. R. A. Angelova, D. Sofronova, N. Nikolova, JMEST, 3, 12 (2016)

2. V. Duakantiene, K. Mikelionyte, AUTEX Res. J. (2019)

3. S. Radavičienè, M. Jucienė, Fibres Text. East. Eur., 20, 3 (2012)

4. S. Radavičienè, M. Juciene, Ž. Juchnevičienè, L. Čepukonè, A. Vilumsone, U. Briedis, I. Baltina, Mat. Sc. (Medžiagotyra), 20, 1 (2014)

5. S. Radavičienė, M. Jucienė, Ž. Juchnevičienė, L. Čepukonė, T. Kleveckas, V. Narvilienè, Mater. Sci., 18, 4 (2012) 
6. S. Radavičienè, M. Jucienè, P. Est. Acad. Sci., 62, 3 (2013)

7. V. Daukantienè, I. Laurinavičiūtè, Int. J. of Cloth. Sci. Tech., 25, 5 (2013)

8. M. Șuteu, L. Indrie, M. A. Prichici, J. Econ. Manag. Inf. Tech., 4, 2 (2015)

9. M. Șuteu, L. Indrie, S. Gherghel, A. Albu, Ann. Univ. Oradea, Fasc. Textile Leatherwork, 15, 2 (2014)

10. M. Șuteu, Indust. Text., 67, 4 (2016)

11. C. F. Baban, M. Baban, E. Toth (Kiss), P. 19th World Text. Conf. - AUTEX(2019) 